\title{
Induction of ovarian toxicity in the freshwater fish, Pseudetroplus maculatus (Bloch, 1795) after sublethal exposure of dibutyl phthalate
}

\author{
K. Sajla ${ }^{1}$, K. P. Raibeemol ${ }^{2}$, K. C. Chitra ${ }^{3^{*}}$ \\ ${ }^{1,2,3}$ Endocrinology and Toxicology Laboratory, Dept. of Zoology, University of Calicut, Kerala, India \\ *Corresponding Author: kcchitra@yahoo.com, Tel.: +91-94951-35330
}

Available online at: www.isroset.org

Received: 02/Oct/2019, Accepted: 15/Oct/2019, Online: 31/Oct/2019

\begin{abstract}
Dibutyl phthalate, a plasticizer, is widely used as a softener in several commercial industrial products. The study investigated the sublethal effects of dibutyl phthalate on ovary of the freshwater fish, Pseudetroplus maculatus. Dibutyl phthalate exposed at $0.2 \mathrm{mg} / \mathrm{L}$ concentration for 24,72 and $96 \mathrm{~h}$ showed behavioural modifications in the fish. The body weight showed significant reduction after $72 \mathrm{~h}$ of toxicant exposure with concomitant increase in mucous deposition, which indicated whole-organism response against the toxicant. The weight of ovary and gonadosomatic index decreased significantly in all treatment groups thereby suggested the stress exhibited on female reproductive organ. Dibutyl phthalate prevented normal activities of steroidogenic enzymes as $3 \beta$ - and $17 \beta$-hydroxysteroid dehydrogenase in ovary of the fish. The alterations in the level of vitellogenin measured through indirect endpoints such as alkali-labile phosphoprotein and total protein in ovary and blood plasma indicated the estrogenic effects of the toxicant. Dibutyl phthalate disrupted hypothalamo-pituitary-gonadal axis as demonstrated by the increase in the levels of luteinizing hormone and testosterone with reduction in serum estradiol without remarkable changes in the level of follicle stimulating hormone. In the ovary, number of vitellogenic oocyte increased whereas the population of pre-vitellogenic oocyte declined without any changes in the number of post-vitellogenic oocyte. Histological evaluation revealed severe morphological damages associated to apoptosis such as empty follicle and atretic oocytes, membrane blebbing, nuclear condensation, vacuolization and broken theca granulosa membrane. The present findings suggested that sublethal exposure of DBP induced ovarian toxicity in the freshwater fish, Pseudetroplus maculatus.
\end{abstract}

Keywords - Dibutyl phthalate, Steroidogenic enzymes, Hormones, Sublethal toxicity, Histology, Pseudetroplus maculatus

\section{INTRODUCTION}

Any man-made modifications in the physical, chemical and biological characteristics of water, which ultimately result in unsuitable use of water resources to humans and aquatic animals, are called aquatic pollution. Freshwater environment is considered as an immediate suitable place for the disposal of sewage and toxic wastes, which can be recycled to some extend where the excess of wastes are drained off into the sea. However, the exponential growth of human population, progressive industrialization, and intensive agricultural practices raise the pollutant load and exploit the water resources to meet the requirements of the ever-increasing population, and also causes serious threats to aquatic organisms [1,2].

The toxicity of contaminants in aquatic ecosystem mainly depends on several factors like the concentration of toxicant that reaches the organism or the affinity of target receptor in organism, time of exposure, mode of persistence in the environment, nature of solubility in water, characteristics of external barriers of organism, and nature of vital systems in the body. The pollutants from contaminated aquatic environments enter into the body of the fishes and other aquatic organisms in different ways including direct absorption through the skin, uptake of contaminated water through gill and mouth during the time of respiration, and feeding behaviour. The toxicants may also interfere with several physiological processes along with change in the normal behavioural patterns of fish and other organisms without causing mortality [3].

Plasticizers are colourless and odourless esters, mainly phthalates, used in polyvinylchloride (PVC) to improve flexibility and durability. Plasticizers are otherwise known as softeners, which reduce the intensity of intermolecular interaction and increase the mobility of polymer chains. This property helps to achieve lower glass transition temperature, hardness, strength and increase flexibity of polymer [4]. Plasticizers also functions as an internal lubricant and reduce friction between polymer chains as they slide against each other in opposing directions. Low volatility and different degrees of miscibility with polymers makes the plasticizers more flexible and durable products. The chemical structure 
of plasticizers is very diverse that belong to various classes of organic compounds including fluorinated substances, hydrocarbons, esters, ketones, alcohols, amines, fats, oligomers and others [5].

Dibutyl phthalate (DBP) is a colourless or very faintly yellow, oily liquid with faint pleasant smell used in making flexible plastics and are found in a variety of consumer products [6]. DBP is a special class of plasticizer often used in combination with other higher molecular weight phthalates. It is produced by the reaction of n-butanol and phthalic anhydride. DBP is widely used in several consumer end products such as vinyl fabrics, floor tiles, car interiors, food wraps, rain coats, shower curtains and other plastic products [6]. The half-life of dibutyl phthalate in soil is only for few days and is considered as relatively non-persistent in air, surface water and soil [7]. DBP from the atmosphere is known to washout through rainfall or dry deposition into aquatic environment. The photo oxidation half-life of dibutyl phthalate in air ranges from $7.4 \mathrm{~h}$ to 3.1 days and in water it is reported as 144 days. However, the biodegradation halflife of dibutyl phthalate in natural surface waters ranges from one to 14 days, and two to 23 days in groundwater, and in soil [8].

Food is the largest source of exposure to dibutyl phthalate, possibly from fish and other seafoods where the exposure levels in fish ranged from 78 to 200 parts per billion. DBP was also detected in some drinking water supplies at levels ranging from 0.1 to $5 \mathrm{ppb}$ [9]. DBP is considered as an endocrine disrupting chemical suggesting antiandrogenic effect in fish [10]. Administration of DBP induced alterations in male reproductive tract development, and altered fetal steroid hormones and genes in rats [11]. DBP is known to alter ovarian function in mice at doses relevant to humans [12]. In embryos of Xenopus laevis, DBP disrupted cleavage divisions, slowed cytokinesis, cellular dissociation thereby caused mortality [13].

DBP are the known peroxisome proliferator, widely detected in aquatic environments that have potential ability to accumulate in biological organisms because of its lipophilic property. Thus it can be transferred from mothers to eggs through egg lipids and can adversely affect the development of an organism, sexual determination and differentiation [8]. Pre-natal exposure of DBP in humans showed the presence of the compound along with its metabolites in pregnant women and in breast milk. DBP when transferred from the mother causes negative impact on infants and the health effects seen in children are found similar to the effects seen in adults [14].

Fish is a representative of vertebrate species that have high degree of sequence and functional homology to mammals, including humans. Fish consist of diverse members so it makes them a valuable bioindicator of the aquatic environment pollution. Thus most of the ecotoxicological studies were performed using fish as a model organism and can be used for both the field and laboratory studies. Relatively small size, simple way of existence in the natural environment, high fecundity rate, inexpensive, easy to handle and maintenance in laboratory conditions are the attractive factors that gives priority to fish as the suitable animal model. Fish consist of well-developed osmoregulatory, endocrine, nervous and immune system [15]. On comparison with other vertebral life forms, fish are the more sensitive, and highly responsive to various toxicants in the aquatic environment. Toxicants that are released into the aquatic ecosytems easily enter into the body of fish through dermal contact, gill and mouth at the time of respiration and ingestion through the food chain. Thus any slight deviations in the normal biological condition of the aquatic environment are immediately reflected as the alteration in physiology and behaviour of exposed fish [3]. Thus in the current study Pseudetroplus maculatus was used as a laboratory model to assess the toxic effects of one of the phthalate plasticizers, dibutyl phthalate.

External and internal cues are known to influence the endocrine system, which could cause direct effects on the fish reproduction. Defects in the reproductive system could ultimately leads to decline in the fish population. In this point of view, a hypothesis was set to assess the effect of one of the environmental pollutants possessing endocrine disrupting properties, namely dibutyl phthalate on the ovarian system of the freshwater cichlid fish, Pseudetroplus maculatus.

\section{RELATED WORK}

Salazar et al. (2004) worked on "The effect of oral intake of dibutyl phthalate on reproductive parameters of Long Evans rats and pre-pubertal development of their offspring".

Bhatia et al. (2014) worked on "The estrogenic effects of dibutyl phthalate in adult male Murray rainbow fish (Melanotaenia fluviatilis)".

Bhatia et al. (2015) worked on "Inhibition in the body growth and gonadal development after long-term exposures to dibutyl phthalate in juvenile Murray rainbowfish (Melanotaenia fluviatilis)".

Sen et al. (2015) worked on "Disruption of ovarian function in young CD-1 mice after short-term exposure to dibutyl phthalate".

\section{METHODOLOGY}

\section{Maintenance of animal:}

Adult freshwater cichlid fish, Pseudetroplus maculatus weighing $5 \pm 1 \mathrm{~g}$ and $7 \pm 1 \mathrm{~cm}$ length were collected from Angel fish farm, Chalakudy, Thrissur district, Kerala, India. The fishes were brought to the laboratory with least disturbance in well-aerated polythene bags and acclimatized to the laboratory conditions for 15 days before commencing 
the experiments and sustained with constant supply of dechlorinated freshwater and the good lighting system $(12 \mathrm{~h}$ light: $12 \mathrm{~h}$ dark) in $40 \mathrm{~L}$ capacity glass aquarium tank. The health status of the fish was continuously monitored throughout the experiments.

The physico-chemical features of the tap water were analysed as per American Public Health Association guidelines [16]. The standardized physico-chemical features of water were maintained in control and treatment groups, throughout the experiments. Water temperature in the test ranged at $28 \pm 2{ }^{\circ} \mathrm{C}$, oxygen saturation of water ranged between 70 and $100 \%$, and $\mathrm{pH}$ ranged between 6.5 and 7.5.

\section{Experimental design:}

The median lethal concentration of dibutyl phthalate for $96 \mathrm{~h}$ $\left(\mathrm{LC}_{50}-96 \mathrm{~h}\right)$ in Pseudetroplus maculatus determined by probit analysis was $2 \mathrm{mg} / \mathrm{L}$ concentration. Based on the $\mathrm{LC}_{50}-96 \mathrm{~h}$ value, one-tenth of median lethal concentration of dibutyl phthalate were selected as sublethal concentration i.e., $0.2 \mathrm{mg} / \mathrm{L}$. Fishes were exposed to single sublethal dose of dibutyl phthalate for short-term durations such as 24,72 , $96 \mathrm{~h}$, respectively along with negative and solvent (propylene glycol) control fishes with ten specimens in each groups. Activities of steroidogenic enzymes in ovary, concentration of vitellogenin in ovary and blood plasma of female fish, level of different hormones and histopathology of ovary were evaluated during the experiment.

\section{Sample collection:}

At the end of every last treatment period, fish were caught very carefully by using a small dip net, one at a time with least disturbance. Total body weights together with and without body surface mucous deposition were recorded instantly after the end of each exposure period. Mucous deposition was calculated by taking the deviations of the body weight and expressed in percentage.

Blood samples were collected from both control and test of female fishes, using fine syringe by the cardiac puncture method. Fresh blood sample collected in the vial containing anticoagulant were kept undisturbed at room temperature for 15-30 min, centrifuged at $800 \mathrm{~g}$ for $10 \mathrm{~min}$ to obtain blood plasma for vitellogenin analysis. Blood serum collected by centrifuging the remaining blood at $1700 \mathrm{~g}$ for $10 \mathrm{~min}$ at $4^{\circ} \mathrm{C}$ was used for hormone analysis. Both serum and plasma samples were then stored at $-80^{\circ} \mathrm{C}$ until used.

After collecting the blood samples, the ovary tissues were dissected were used for biochemical and histopathological examinations. The ovary weight of control and treated fish groups were recorded to evaluate gonadosomatic index. The collected ovary was cleaned from debris and homogenate $(1 \% \mathrm{w} / \mathrm{v})$ of ovary were prepared in phosphate buffer $(\mathrm{pH}$ 7.4) by using a motor-driven glass Teflon homogenizer on crushed ice for a minute. The homogenate was centrifuged at
$800 \mathrm{~g}$ for 15 minutes at $4^{\circ} \mathrm{C}$ so as to obtain the supernatant, which was then used for analysis of steroidogenic enzymes

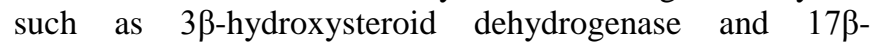
hydroxysteroid dehydrogenase [17], and vitellogenin concentration using indirect endpoints such as alkali-labile phosphoprotein [18] and total protein concentration [19] in plasma and ovary.

\section{Hormone analysis:}

Serum levels of follicle stimulating hormone (FSH), luteinizing hormone ( $\mathrm{LH})$, testosterone and estradiol were analysed by commercial enzyme linked immunosorbant assay (ELISA) kits obtained from Diagnostic System Laboratories, USA.

\section{Histopathology of ovary:}

Ovary collected by sacrificing the female fish was rinsed in physiological saline to remove the blood and debris. The tissue was fixed in $10 \%$ buffered formalin for 24 to $48 \mathrm{~h}$ for histological procedures. The tissue was dehydrated in ascending grades of ethanol and cleared in xylene until the tissue become translucent. Then transferred to molten paraffin wax for $1 \mathrm{~h}$ to remove xylene completely and impregnated with wax. The blocks were cut and sections of thickness 4 to 6 microns were prepared using rotary microtome. The sections were stained with haematoxylin and eosin and mounted in DPX [20]. The slides were observed for structural alternations under light microscope and compared with that of control tissues. Photomicrographs were taken using cannon shot camera fitted to the Carl Zeiss Axioscope-2 plus Trinocular Research microscope.

\section{Statistical analyses:}

Statistical analysis was performed by using one-way analysis of variance (ANOVA) followed by Duncan's multiple range test using statistical package SPSS 19.0. Differences were considered to be significant at $\mathrm{P}<0.05$ against control groups. Data are presented as Mean \pm SD for ten animals per group. All experiments were carried out in duplicates to minimize statistical errors.

\section{RESULTS}

\section{Effect of DBP on behavioural modifications in the fish, Pseudetroplus maculatus:}

The fish subjected to DBP showed drastic behavioural modifications when compared to the control fish groups. After the introduction of the toxicant, fishes showed vibrant swimming which gradually decreased to erratic movement and finally become slow and lethargic at the end of exposure period. Besides, fish gasped for air swimming at the top of the aquarium tank, and knocked on the wall of fish tanks during the experimental period. High degree of mucous production, increased surfacing i.e., maintaining the movement of fish at the water surface, imbalance of the body and incapability to maintain normal body posture are the 
other different behavioural changes observed during the time of DBP treatment.

\section{Effect of DBP on body weight and mucous secretion:}

After DBP exposure there was a significant $(\mathrm{P}<0.05)$ reduction in the body weight of animal, after 72 and $96 \mathrm{~h}$, when compared to the control groups (Figure 1). DBP exposure significantly $(\mathrm{P}<0.05)$ increased the production of mucous throughout the body of animal in time-dependent manner than the respective control groups (Figure 2).

\section{Effect of DBP on the weight of ovary and gonadosomatic index (GSI):}

The weight of the ovary showed significant $(\mathrm{P}<0.05)$ decrease after DBP exposure at $0.2 \mathrm{mg} / \mathrm{L}$ concentration after 72 and $96 \mathrm{~h}$ (Figure 3). Similarly, the gonadosomatic index (GSI) of the ovary also showed a significant $(\mathrm{P}<0.05)$ decrease in time-dependent manner after 72 and $96 \mathrm{~h}$ of DBP exposure when compared to the control groups (Figure 4).

\section{Effect of DBP on the activities of steroidogenic enzymes:}

The activities of $3 \beta$-hydroxysteroid dehydrogenase ( $3 \beta$-HSD) and $17 \beta$-hydroxysteroid dehydrogenase (17 $\beta$-HSD) enzymes in ovary of the fish, Pseudetroplus maculatus showed significant $(\mathrm{P}<0.05)$ reduction after sublethal exposure to DBP in time-dependent manner when compared to the corresponding control groups (Figure 5).

\section{Effect of DBP on the level of vitellogenin:}

The indirect endpoints of vitellogenin such as alkali-labile phosphoprotein (ALP) and total protein concentration in ovarian tissue and plasma of female fish showed alterations after DBP exposure. The level of ALP showed significant $(\mathrm{P}<0.05)$ increase in ovarian tissue while there was significant $(\mathrm{P}<0.05)$ reduction in the level of ALP after 72 and $96 \mathrm{~h}$ of DBP treatment in blood plasma of female fish (Figures 6 and 7). The concentration of total protein in ovary and plasma increased significantly $(\mathrm{P}<0.05)$ after DBP exposure at sublethal concentration (Figures 8 and 9).

In ovary, correlation analysis between alkali-labile phophoprotein and total protein concentration showed high degree of positive correlation with ' $r$ value' as +0.98 and the regression equation $\mathrm{y}=0.008 \mathrm{x}+1.082$; and $\mathrm{r}^{2}=0.979$ (Figure 10). However, in plasma the correlation co-efficient between alkali-labile phophoprotein and total protein concentration showed high degree of negative correlation with ' $r$ value' as -0.80 and the regression equation as $\mathrm{y}=-$ $0.940 \mathrm{x}+1.595$; and $\mathrm{r}^{2}=0.65$ (Figure 11).

\section{Effect of DBP on serum hormone level:}

Fish exposed to DBP at $0.2 \mathrm{mg} / \mathrm{L}$ concentration for $96 \mathrm{~h}$ showed no remarkable changes in the level of follicle stimulating hormone (Figure 12) whereas the levels of luteinizing hormone (Figure 13) and testosterone (Figure 15) increased significantly $(\mathrm{P}<0.05)$ with reduction in the level of estradiol (Figure 14) when compared to the corresponding control groups.

Effect of DBP on ovarian follicular population:

Sublethal exposure of DBP for $96 \mathrm{~h}$ showed significant $(\mathrm{P}<0.05)$ increase in the number vitellogenic oocyte while the population of pre-vitellogenic oocyte showed significant $(\mathrm{P}<0.05)$ reduction, and there was no significant changes in the number of post-vitellogenic oocyte in the ovary of the fish, Pseudetroplus maculatus (Figure 16).

\section{Effect of DBP induced apoptotic changes in ovary of the fish:}

Induction of apoptosis after DBP exposure for $96 \mathrm{~h}$ was documented by several morphological changes in the oocytes such as membrane blebbing (2.22\%), nuclear condensation $(15.5 \%)$ and break in the theca granulosa (20\%) in all phases of oocytes (Figure 17). No such morphological changes associated to apoptosis were noticed in both control groups.

\section{Effect of DBP on histopathology of ovary:}

Ovary of control and propylene glycol (solvent) exposed fishes showed normal histoarchitecture having different stages of oocytes such as pre-vitellogenic, vitellogenic and post-vitellogenic (Figures 18A and B). Sublethal exposure of DBP for $96 \mathrm{~h}$ showed morphological changes associated to apoptosis such as empty follicle and atretic oocytes (Figure 18C), membrane blebbing (Figure 18D), nuclear condensation (Figure 18E), vacuolization and broken theca granulosa membrane (Figure 18F).

\section{DISCUSSION}

Several ecological studies have proposed behaviour as a promising and ecologically relevant monitoring tool, and assessment of fish behaviour was considered as the highly sensitive method to indicate the presence of toxicants in the aquatic environment. The normal behaviour of fish follows specific physiological sequences, which are triggered by external stimuli acting through neural networks [21]. Any disturbance in the sequences of neuronal networks ultimately results in detrimental behavioural modifications. Numerous physiological and environmental factors also influence the initiation of the sequences. Toxic effects of aquatic contaminants are responsible for change in the environmental and physiological stimuli that could lead to inappropriate behavioural pattern [21]. Toxicant-induced behavioural alterations pose serious risks to the success of fish population. In the current study, sublethal exposure of DBP caused severe behavioural modifications in fish when compared to the control groups. Initial exposure to DBP showed vibrant swimming which gradually decreased to erratic movement, and finally become slow and lethargic at the end of exposure period. 
The swimming ability of fish is crucial for the survival as it reflects constant adaptation through direct interaction with physical, chemical, social, and physiological aspects of the environment [22]. The stability in fish locomotion provides the best opportunity for survival and reproductive success by enabling organisms to efficiently exploit resources and define suitable habitats [23]. During DBP exposure, fish gasped air from the top of the aquarium tank, and knocked on the wall of tanks to avoid exposing the toxicant. High rate of mucous production, increased surfacing i.e., staying mostly at the water surface, change in the swimming orientation and normal body posture were also observed after DBP treatment. This could be due to the toxic effects of DBP represented as an integrated, whole-organism response. The study showed an agreement to another study on exposure to sublethal concentration of DBP in juvenile Nile tilapia has been known to cause unusual swimming, restlessness, mucous secretion, breathing difficulties such as speedy respiration and rapid opercular movement [24]. Similarly, DBP and DEP exposed to Cyprinus carpio fingerlings also showed wide range of abnormal behaviour like erratic swimming, rapid opercular movement, surfacing, air gulping and abundant mucous secretion [25]. The altered responses of fish behaviour after DBP exposure could be associated with reduced fitness and survival, which eventually result in adverse consequences at the population level. However, recent advanced technologies such as computer-assisted and video automated evaluation to quantify the behavioural data was not performed as the present study focused on ovarian toxicity than behavioral endpoints.

Measures of body weight were routinely evaluated parameter in toxicology studies as it interprets compound-related effects on exposed animals. The body weight of the animals was measured at the end of every treatment period, and it was observed that DBP exposure for 72 and $96 \mathrm{~h}$ reduced the weight of animal when compared to the corresponding control groups. The present inference suggested that the reduction in body weight could be due to the treatmentrelated effect. Combined exposure of three different phthalate esters namely DBP, di (2-ethylhexyl) phthalate (DEHP) and acetyl tributyl citrate (ATBC) at environmentally relevant concentration have demonstrated similar reduction in body weight on the adult female zebrafish [26].

DBP exposure increased the production of mucous throughout the body of animal than the respective control groups. Mucous acts as a dynamic physical and biochemical barrier against abrasion, environmental toxins, and pathogens. Besides, mucous production displays several biological and ecological roles such as osmoregulation, parental feeding, and chemical communication [27]. Fish mucous mainly consists of mucin, however in addition it also contains numerous immune molecules, such as lysozymes, immunoglobulins, complements, lectins, antimicrobial peptides, and other molecules like mycosporine-like amino acids, toxins, and kairomones that mediate interspecific interactions by providing information that benefits individuals of another species [28]. However, high rate of mucous production observed after DBP exposure might be a defensive mechanism of fish against the entry of toxicants into the body, and thus functioned as physical barrier to the exposed phthalate. It has been reported that mucous secretion also functions for intraspecific communication, either as attracting cues or alarm cues [29]. The present findings suggested that the production of mucous was probably an alarming cue against DBP exposure.

Evaluation of organ weight is one of the most sensitive indicators in toxicology studies. Changes in the organ weights are often associated with treatment-related effects. Weight of organs studied in toxicology studies are mainly used to understand the mechanism of action, metabolism, toxicokinetics, and the physiology of specific organ related to the test species [30]. In the present study, the weight of the ovary was measured after sublethal exposure of DBP at 0.2 $\mathrm{mg} / \mathrm{L}$ concentration. The findings showed reduction in organ weights after 72 and $96 \mathrm{~h}$, and this could be due to the stress exhibited by the toxicant on female reproductive tract. Quantification of organ weights to body weight help in eliminating variations due to body weight differences. Hence in the present study, the relative organ weight or gonadosomatic index (GSI) was measured, which showed significant reduction in time-dependent manner after 72 and $96 \mathrm{~h}$ of DBP exposure when compared to the control groups. Generally, alterations in body weight may lead to increase or decrease in some organ-to-body weight ratios, so appropriate evaluation of ovary-to-body weight was performed to evaluate organ toxicity. The study revealed that DBP exposure caused treatment-related alterations in the ovary weight of the fish. Similar reduction in the ovary weight and GSI have been reported in female zebrafish exposed to combined plasticizers namely DBP, DEHP and ATBC, which indicated interruption in gonad development and reproductive impairment [26].

Ovary of fish produces number of steroid products, among which the steroidogenic enzymes, 3 $\beta$-hydroxysteroid dehydrogenase and 17 $\beta$-hydroxysteroid dehydrogenase play a vital role in the steroidogenic pathway. These enzymes regulate certain steroid-dependent events of ovarian development like onset of maturation, vitellogenesis, oocyte growth and maturation, which are mediated by the regulation of steroidogenic genes [31]. Sublethal exposure of DBP caused reduction in the activities of $3 \beta$-hydroxysteroid dehydrogenase and 17 $\beta$-hydroxysteroid dehydrogenase enzymes in ovary of the fish, Pseudetroplus maculatus. The results suggested that DBP disrupted the steroidogenic pathway and caused endocrine disruption by preventing the normal function of steroidogenic enzymes. In vitro exposure of mural granulosa cells to high doses of DBP has been 
shown to alter mRNA expression of steroidogenic, angiogenic, and epidermal growth factor-like genes suggesting negative effects on female fertility [32]. One of the phthalate plasticizers, di-isononyl phthalate (DINP) has been shown to affect gonadal steroidogenesis by the reduction in activities of steroidogenic enzymes in the freshwater fish, Oreochromis mossambicus [33].

Vitellogenin, the precursor to egg protein, is produced by both males and females in response to estrogen or its mimics [34]. The production of vitellogenin is either very low or absent in males and in immature females, whereas mature female fish have a seasonal cycle of serum vitellogenin levels, with peak values reaching tens of milligrams per milliliter [34]. As in all vertebrates, vitellogenesis in the mature female fish is under the hormonal regulation, especially by estradiol, the female-specific major endogenous estrogen. Several reports have suggested that an increase in the titre of estradiol stimulate the liver to produce vitellogenin, which is then transported in the bloodstream to the ovary. In oocyte, vitellogenin enters through specific receptor-mediated endocytosis, where it is cleaved into the smaller yolk proteins namely phosvitin, lipovitellin, and beta-component that get accumulated as yolk globules or granules [35]. Owing to the specific association between vitellogenin synthesis and estrogen stimulation, the evaluation of this protein is considered as a highly specific biomarker for estrogen exposure in fish.

In the present study, vitellogenin was measured using indirect endpoints such as alkali-labile phosphoprotein (ALP) and total protein concentration in ovarian tissue and plasma of female fish. DBP exposure showed increase in the level of ALP in ovarian tissue while there was reduction in the level of ALP in blood plasma. After DBP exposure at sublethal concentration showed increase in the concentration of total protein in ovary and plasma. The present data clearly showed that DBP have profound negative impact on vitellogenesis, which in turn could reduce reproductive success of fish.

Further, the study also performed correlation analysis between alkali-labile phophoprotein and total protein concentration, which showed high degree of positive correlation with ' $r$ value' as +0.98 in ovary of the fish. However, in plasma of fish the correlation co-efficient between alkali-labile phophoprotein and total protein concentration showed high degree of negative correlation with ' $r$ value' as -0.80 . The observed positive correlation of ALP and total protein concentration in ovary revealed that DBP exposure upregulated the vitellogenin level in ovarian tissue. However, the negative correlation in blood plasma indicated that the circulating level of vitellogenin was downregulated after DBP exposure. Thus further research is warranted to elucidate the effects of DBP over a longer exposure period. One of the studies have reported that exposure to DBP increased the circulating level of plasma vitellogenin and adversely affected the reproductive health of male Murray rainbow fish, Melanotaenia fluviatilis by an estrogenic mode of action [36]. In another study, DEHP exposure at environmentally relevant concentration to female zebrafish showed alteration in vitellogenin synthesis thereby interfered reproductive performance of the fish [37].

Development of ovarian follicles, maturation of oocytes, vitellogenesis and ovulation in fish are predominantly controlled by hormones, including the follicle stimulating hormone (FSH) and the luteinizing hormone ( $\mathrm{LH})$, as well as growth factors and other hormones produced by the ovary [38]. However, endocrine disruption can alter both the organizational and activational effects of reproductive hormones, possibly having a profound effect on an organism's ability to reproduce and therefore affect the fitness and well-being in natural population.

FSH and LH are called gonadotropins that stimulate the gonads, either testes in males or ovaries in females, to maintain normal reproductive functions. $\mathrm{LH}$ and FSH are large glycoprotein hormones composed of alpha and beta subunits, where alpha subunit is identical but beta subunit is unique and possess ability to bind with its own receptor [39]. These hormones are secreted from cells of the anterior pituitary called gonadotrophs. FSH stimulates the maturation of ovarian follicles while LH stimulates the secretion of sex steroids from the gonads. In ovary, follicle cells respond to LH stimulation by secretion of testosterone, which is converted into estrogen by adjacent granulosa cells [40]. The principle regulator of LH and FSH secretion is gonadotropinreleasing hormone, a ten amino acid peptide, synthesized and secreted from hypothalamic neurons and binds to receptors on gonadotrophs. Numerous hormones influence $\mathrm{GnRH}$ secretion, and positive and negative control over GnRH and gonadotropin secretion is actually more complex process. Elevated blood levels of gonadotropins usually reflect lack of steroid negative feedback, and it usually occurs when the gonads from either males or females are removed [41].

Fish exposed to DBP for $96 \mathrm{~h}$ showed no remarkable changes in the level of FSH. In most fish species, more levels of FSH secretion occurs during early gonadal development and in the vitellogenic phase while LH secretion remains at low levels during these phases and exhibits a sharp peak at final oocyte maturation and ovulation [42]. The unaltered level of FSH after DBP exposure for $96 \mathrm{~h}$ reflected that the toxicant did not affected the development of ovary. However, DBP exposure acts antagonistic by rise in the level of LH thereby suggesting the disruption of normal endocrine system. Similarly, the level of testosterone was found increased after DBP exposure, and this could be due to the stimulation of LH on the follicle cells of ovary to secrete testosterone. However, the level of estradiol decreased after DBP exposure, and this indicated the failure of steroidogenic 
enzymes for the conversion of testosterone into the potent female hormone, estradiol.

The present findings denoted the estrogenic effects of DBP on ovarian tissue of the fish, Pseudetoplus maculatus. There are no sufficient data available regarding the endocrine disrupting properties of DBP, however, a study on one of the food additives, butylated hydroxyanisole, exposed to common freshwater fish, Anabas testudineus showed tremendous increase in the levels of $\mathrm{LH}$ and testosterone with drastic decrease of estrogen level [43]. The results provide only the baseline data on the estrogenic effect of DBP, and a long-term exposure is essential to find the exact effect of the compound as an endocrine disruptor.

In the present study, sublethal exposure of DBP showed increase in the number vitellogenic oocyte while the population of pre-vitellogenic oocyte decreased without significant changes in the number of post-vitellogenic oocyte in the ovary of the fish, Pseudetroplus maculatus. The reason for the reduction in pre-vitellogenic oocyte might be due to the failure of vitellogenesis and reduction in the level of estradiol owing to DBP exposure in the primary growth phase, which was evident by the disruption in the activities of steroidogenic enzymes. Thus DBP exposure affected both growth phase and maturation phase of oocyte in ovary of the fish. The adverse effects of DBP on oocyte maturation could be due to the failure of incorporating vitellogenin into the growing oocytes. The present finding coincided with another study which showed significant reduction in the circulating levels of vitellogenin in female rainbow fish after DBP exposure [44].

Sublethal exposure of DBP also caused several morphological changes in the oocytes as observed with membrane blebbing $(2.22 \%)$, nuclear condensation $(15.5 \%)$ and break in the theca granulosa $(20 \%)$ in all phases of oocytes. Apoptosis is a genetically determined and biologically functional mode of programmed cell death that occurs in all living organisms. Morphologically, apoptosis is found in ovarian follicles throughout all stages of life. During immature phase, apoptosis is more likely localized to the oocytes, whereas in adult life, it is detected in granulosa cells of secondary and antral follicles [45].

In female gonad, the naturally-occurring apoptosis is very rare as the germ cell wastage do not benefits the reproductive fitness of the animal. However, toxicant-induced apoptosis in ovarian tissue is more prominent, which either results in the loss of oocytes or demise of surrounding granulosa cells necessary to support, nourish and mature the developing oocytes [46]. The present results showed apoptosis in oocytes in the form of distinct morphological changes as membrane blebbing, nuclear condensation and break in theca granulosa layers, which can be collectively referred as follicular atresia. The observed degenerative process after
DBP exposure could be the reason for the substantial decrease in the population of follicles, especially in the previtellogenic phase of oocytes. There was no related data available regarding phthalates-induced ovarian apoptosis in fish, however, a data on DBP induced disruption in the expression of genes involved in cell cycle and apoptosis pathways in mouse antral follicles support the present findings [47]. Similarly, increase in the number of apoptotic ovarian follicles, and associated decline in sex steroid hormones has been reported after dietary methyl mercury exposure to fathead minnows, Pimephales promelas [48].

Histological examination also revealed morphological changes associated to apoptosis such as empty follicle and atretic oocytes, membrane blebbing, nuclear condensation, vacuolization and broken theca granulosa membrane. The apoptotic changes observed in ovarian follicles indicated the stressful condition of fish, which ultimately reduced the follicular population. DEHP, one of the phthalate plasticizers, induced ovarian toxicity have been reported in mouse cells in vitro by associated increase in TUNEL positive oocytes and increased mRNA levels of pro-apoptotic BCL-2-associated X protein [49]. The present findings were in agreement with another study when DBP exposed for 7 days showed reduction in the sizes of early vitellogenic oocytes and an increase in the sizes of perinucleolar and cortical alveolar oocytes in Murray rainbow fish [44].

\section{CONCLUSION AND FUTURE SCOPE}

DBP, one of the endocrine disrupting phthalate plasticizers, selected in the study showed ovarian toxicity in the freshwater fish, Pseudetroplus maculatus. Some of the reproductive endpoints such as gonadosomatic index, ovarian steroidogenic enzyme activities, level of vitellogenin concentration, serum hormone analysis, population of follicle cells and histopathological studies conducted showed sublethal ovarian toxicity of DBP exposed for $96 \mathrm{~h}$.

The information obtained in the current study is very crucial as the observations focused on the risk assessment of DBP that occurs ubiquitous in the natural aquatic environment. However, the study has some limitations as the long-term effect of the toxicant was not performed to analyse certain other important reproductive strategies such as fecundity, and spawning frequency. Ovarian growth, development and maturation in teleost fish is a highly complex process, therefore further study is warranted to evaluate the effects of DBP on reproductive potential of the fish. 


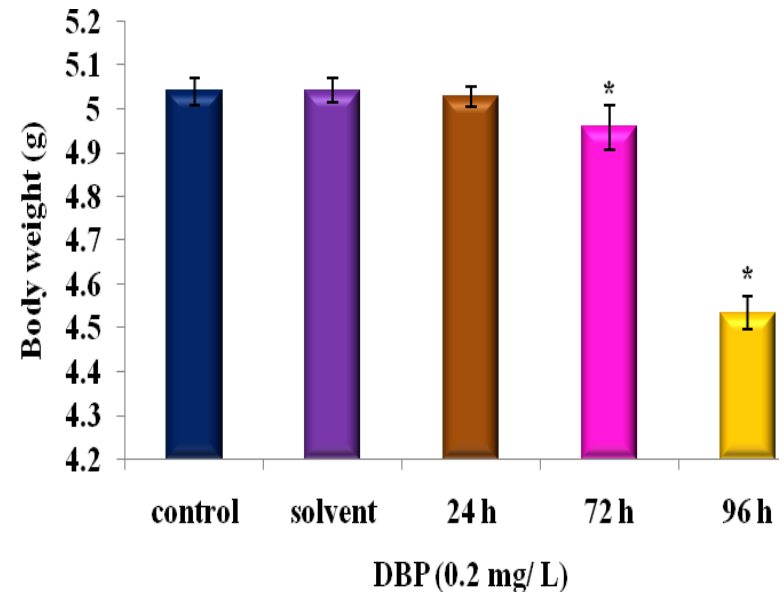

Figure 1 Effect of DBP on the body weight of the fish, Pseudetroplus maculatus

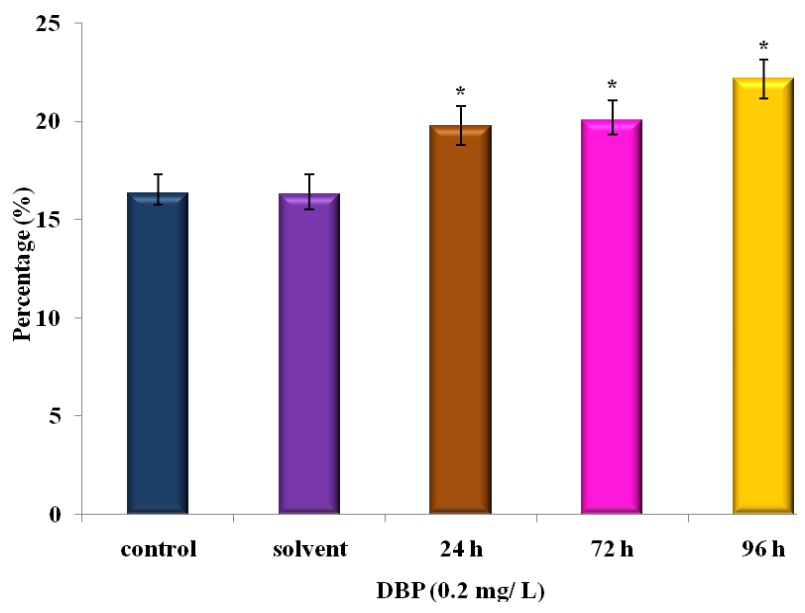

Figure 2 Effect of DBP on mucous secretion in the fish, Pseudetroplus maculatus

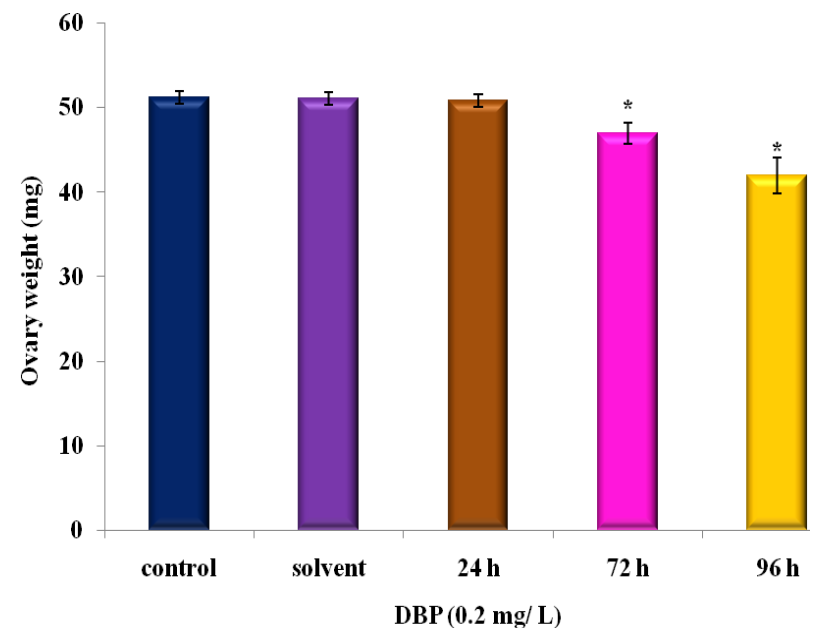

Figure 3 Effect of DBP on the weight of ovary in the fish, Pseudetroplus maculatus

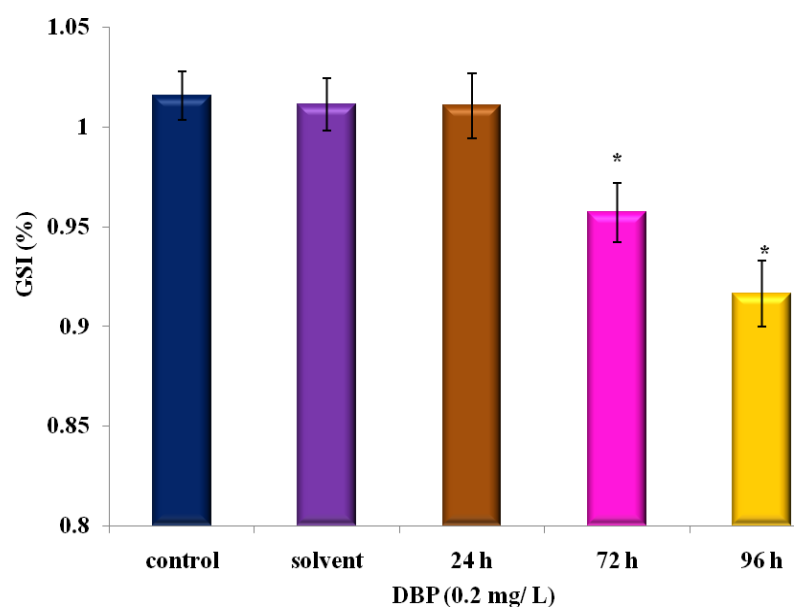

Figure 4 Effect of DBP on the gonadosomatic index of the fish, Pseudetroplus maculatus

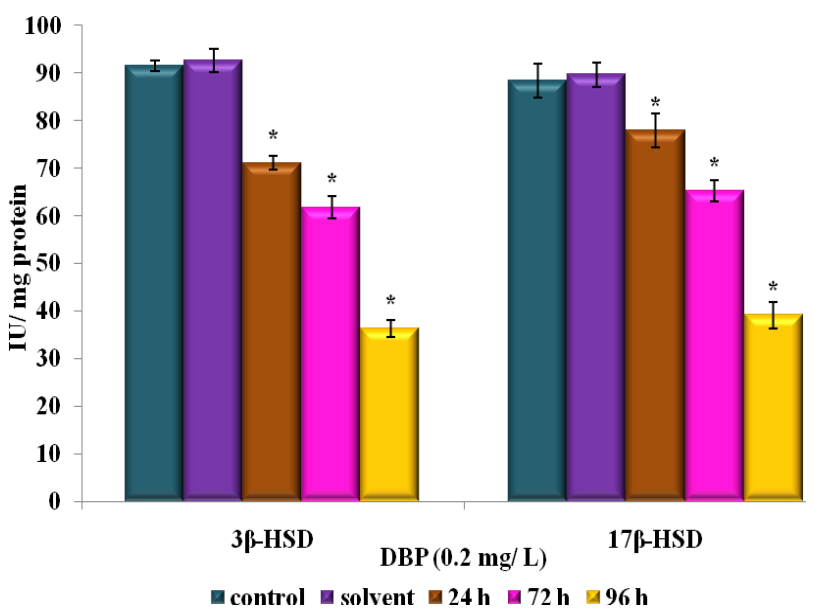

Figure 5 Effect of DBP on the activities of hydroxysteroid dehydrogenase (HSD) enzymes in the ovary of the fish,

Pseudetroplus maculatus

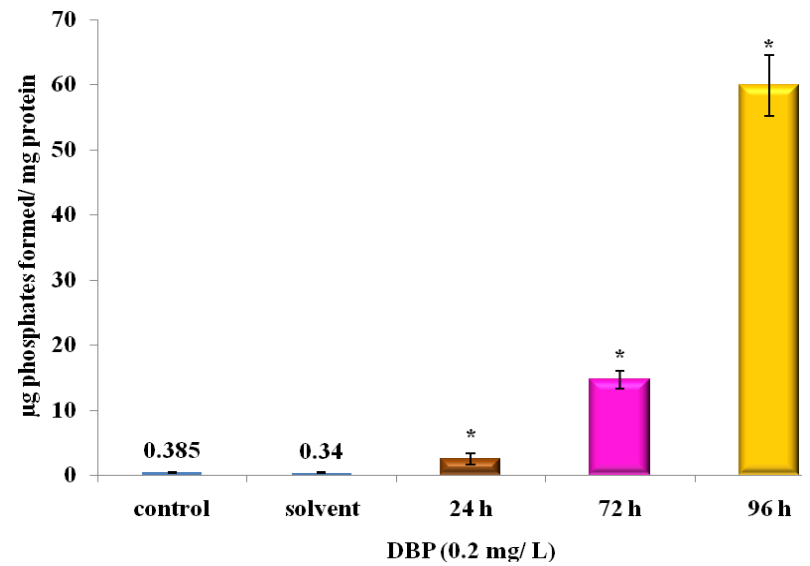

Figure 6 Effect of DBP on the level of alkali-labile phosphoprotein in the ovary of fish, Pseudetroplus maculatus 


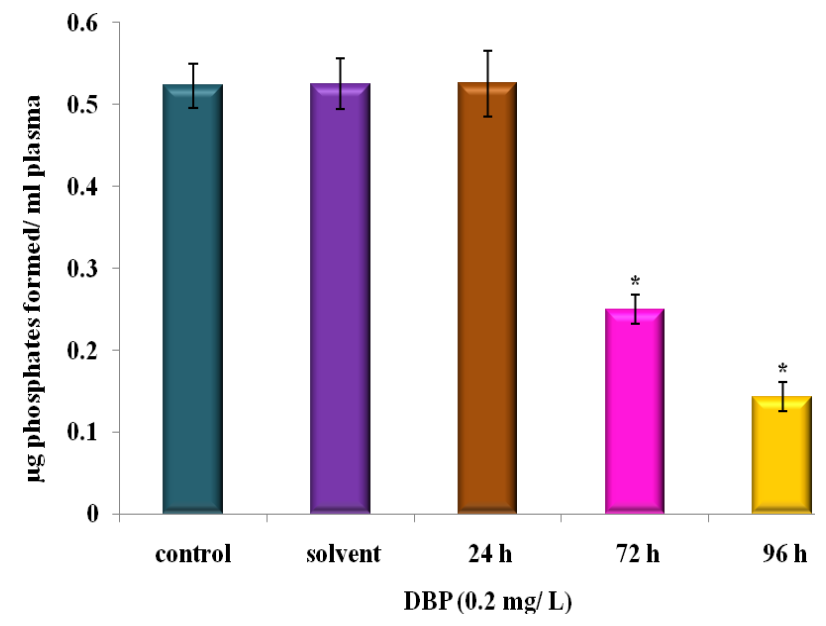

Figure 7 Effect of DBP on the level of alkali-labile phosphoprotein in the plasma of female fish, Pseudetroplus maculatus

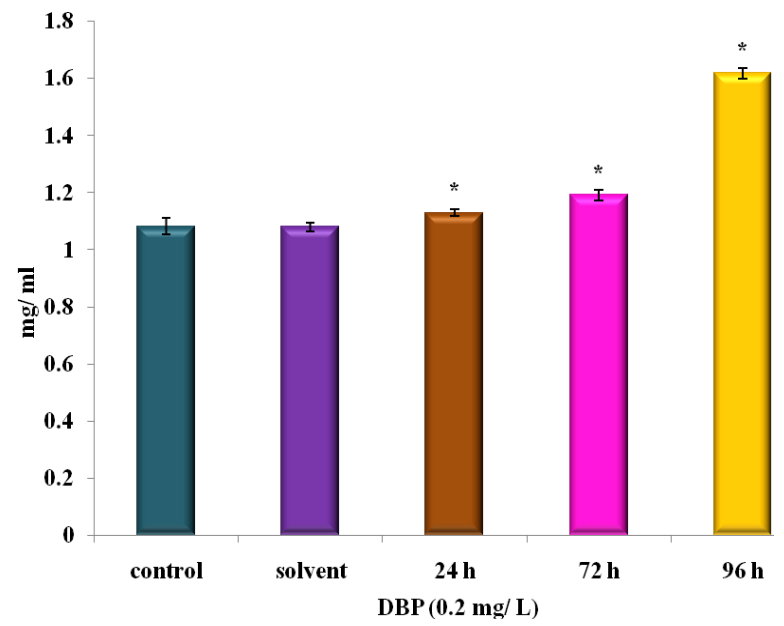

Figure 8 Effect of DBP on the total protein concentration in the ovary of fish, Pseudetroplus maculatus

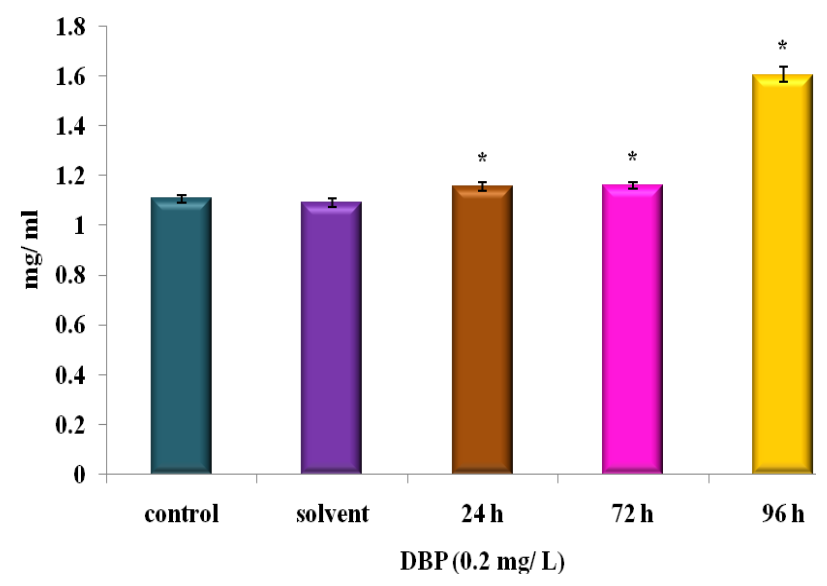

Figure 9 Effect of DBP on the total protein concentration in the plasma of female fish, Pseudetroplus maculatus

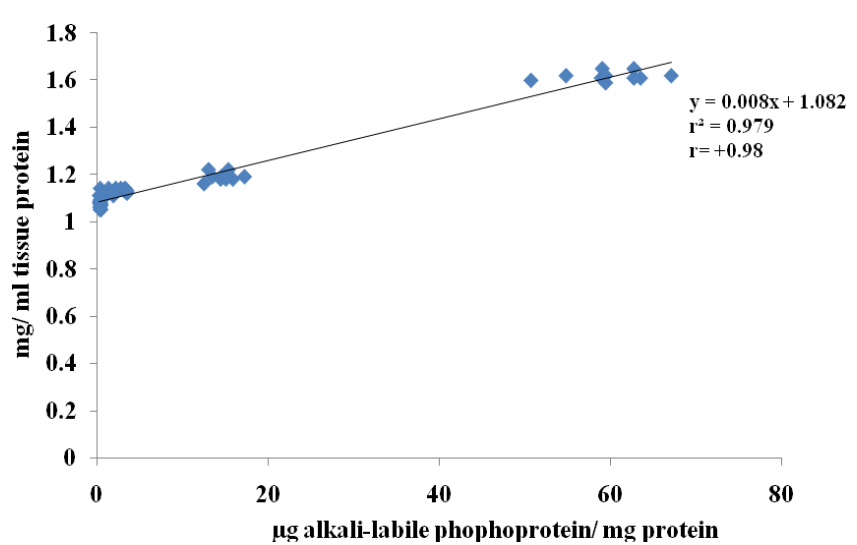

Figure 10 Correlation between alkali-labile phophoprotein and total protein in the ovary of DBP-exposed fish, Pseudetroplus maculatus

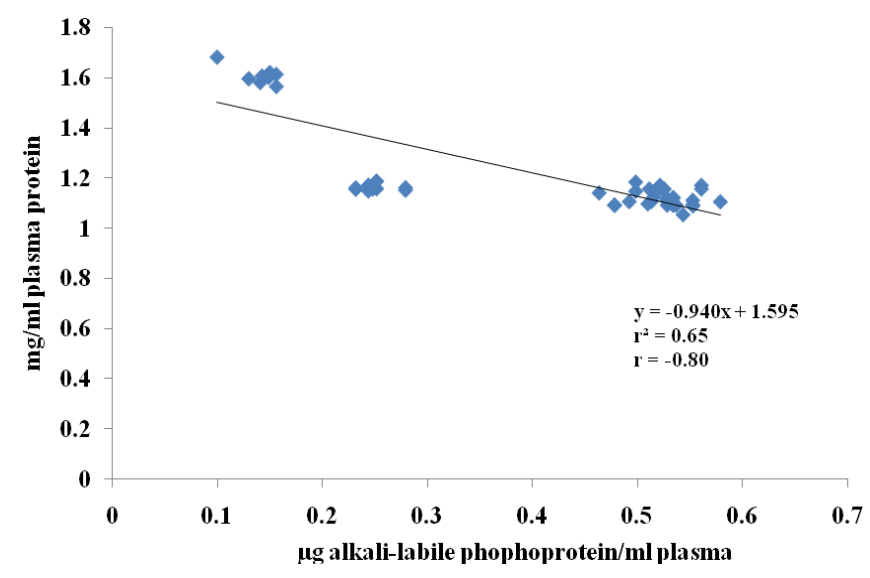

Figure 11 Correlation between alkali-labile phophoprotein and total protein in the plasma of DBP-exposed female fish,

Pseudetroplus maculatus

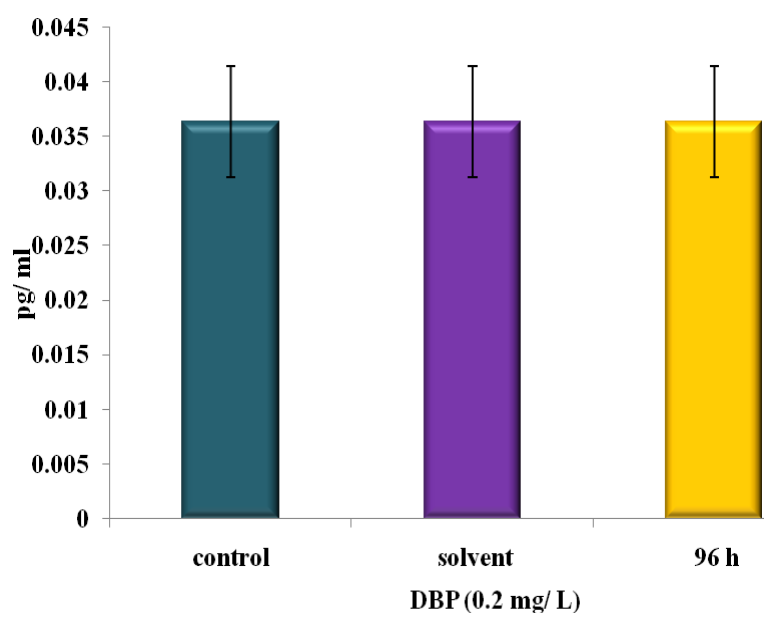

Figure 12Effect of DBP on the level of follicular stimulating hormone in serum of the fish, Pseudetroplus maculatus 


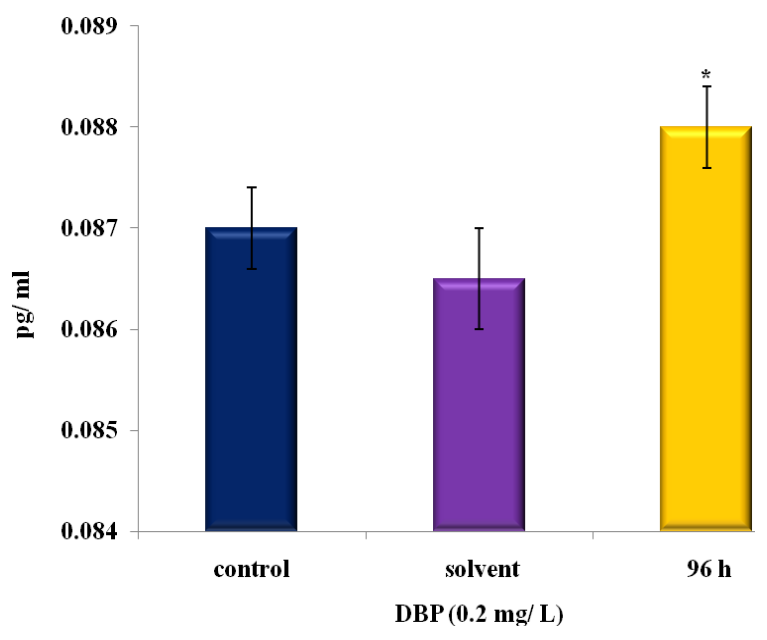

Figure 13Effect of DBP on the level of luteinizing hormone in serum of the fish, Pseudetroplus maculatus

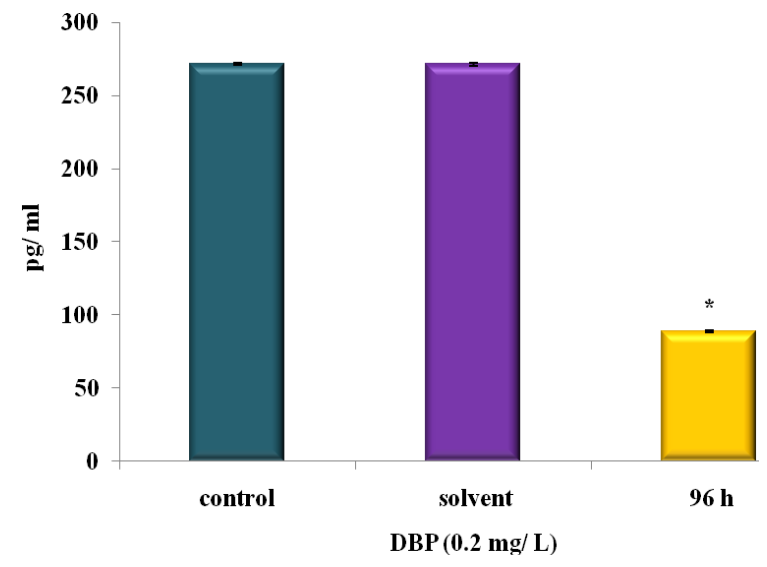

Figure 14 Effect of DBP on the level of estradiol in serum of the fish, Pseudetroplus maculatus

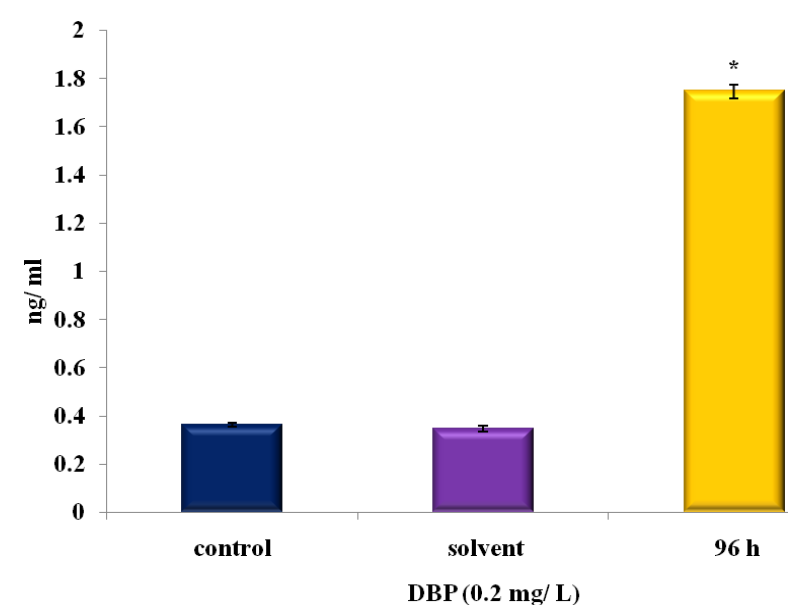

Figure 15 Effect of DBP on the level of testosterone in serum of the fish, Pseudetroplus maculatus

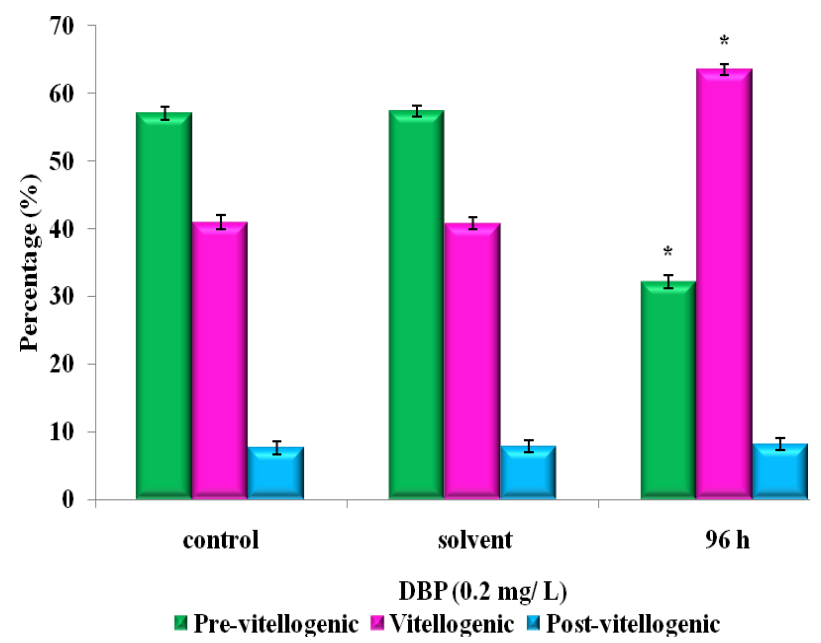

Figure 16 Effect of DBP on the number of follicles at different stages of ovary in the fish, Pseudetroplus maculatus

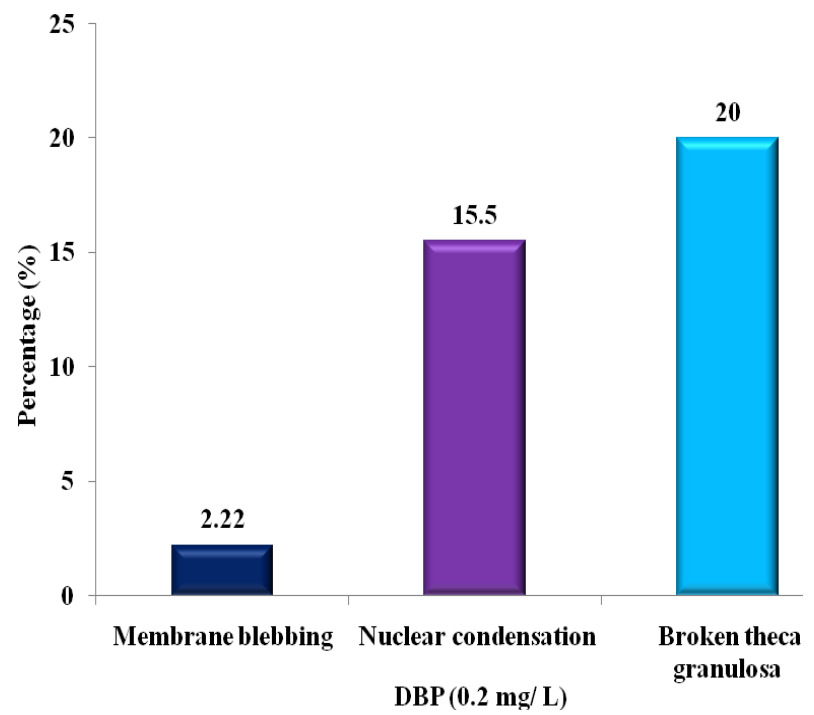

Figure 17 Effect of DBP induced apoptotic changes in ovary of the fish, Pseudetroplus maculatus 


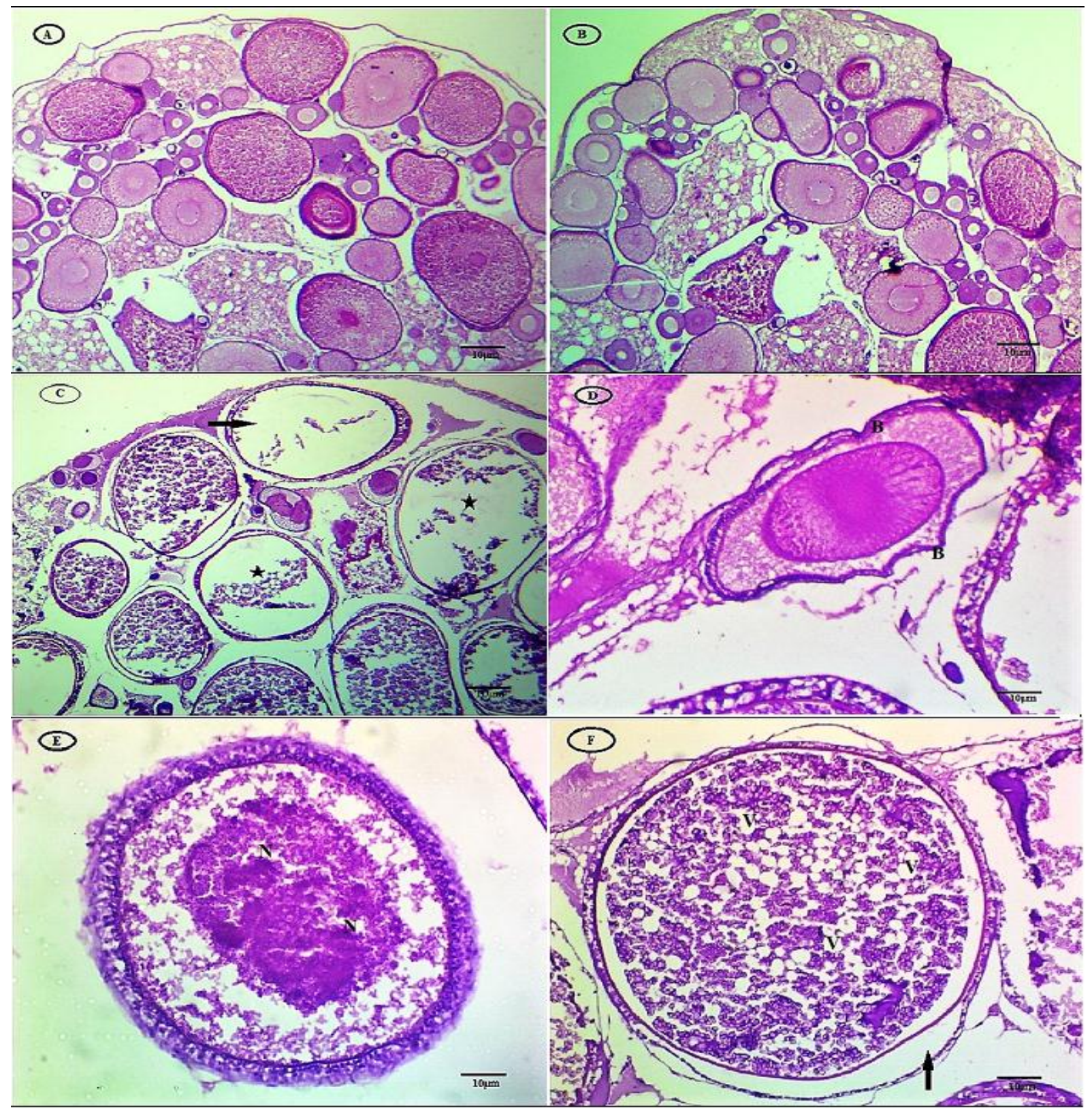

Figure 18 Histological sections of ovary of the fish, Pseudetroplus maculatus stained with haematoxylin and eosin. A-control; $B$ - propylene glycol (solvent-treated); C-F-Ovarian tissue exposed to DBP $(0.2 \mathrm{mg} / \mathrm{L})$ for $96 \mathrm{~h}$ showing empty follicle $(\rightarrow)$ ), atretic oocytes $(*)$, membrane blebbing $(B)$, nuclear condensation $(N)$, vacuolization $(V)$ and broken theca granulosa $(\uparrow)$.

\section{REFERENCES}

[1] C.E. Boyd, "Water quality management for pond fish culture", Elsevier Scientific Publishing Co. ISBN-13:318, 1982.

[2] S. N. Ali, M. Akhtar, A. K. Pandey, "Studies on the role of metallic pollution in riverine ecosystem", Asian Journal of Environmental Science, Vol. 4, Issue 1, pp. 92-94, 2009.

[3] K. A. Solman, P.L. McNeil, "Using physiology and behaviour to understand the responses of fish early life stages to toxicants", Journl of Fish Biology, Vol. 81, Issue 7, pp. 2175-2198, 2012.
[4] S. L. Rosen, "Fundamental principles of polymeric materials". New York: John Wiley and Sons Inc, pp. 82-101, 1993.

[5] B. Bouchoul, M.T. Benaniba, V. Massardier, "Thermal and mechanical properties of bio-based plasticizers mixtures on poly(vinyl chloride)", Polimeros Vol. 27, Issue 3, pp. 237-246, 2017.

[6] Agency for Toxic Substances and Disease Registry (ATSDR), "Toxicological profile for di-n-butyl phthalate", Atlanta, GA: U.S. Department of Health and Human Services. Public Health Service, 1990.

[7] WHO (World Health Organization)/UNEP (United Nations "Environment Programme /IPCS (International Programme on Chemical Safety). Di-n-butyl phthalate - Environmental health 
criteria", 189. ISBN 924571896 (NLM Classification: QV 612) ISSN 0250-863X, 1997.

[8] C.A. Staples, D.R. Peterson, T.F. Parkerton, W.J. Adams, "The environmental fate of phthalate esters: a literature review", Chemosphere Vol. 35, Issue 4, pp. 667-749, 1997.

[9] US. Environmental Protection Agency, "Integrated risk information system (EPA-IRIS) on di-n-butyl phthalate", National Center for Environmental Assessment, Office of research and development, Washington, DC, 1999.

[10] K.A. Aoki, C.A. Harris, I. Katsiadaki, J.P. Sumpter, "Evidence suggesting that di- n- butyl phthalate has antiandrogenic effects in fish", Environmental Toxicology and Chemistry, Vol. 30, Issue 6, pp. 1338-1345, 2011.

[11] K. L. Howdeshell, J. Furr, C.R. Lambright, C.V. Rider, V.S. Wilson, L.E. Gray Jr, "Cumulative effects of dibutyl phthalate and diethylhexyl phthalate on male rat reproductive tract development: altered fetal steroid hormones and genes", Toxicological Sciences, Vol. 99, Issue 1, pp. 190-202, 2007.

[12] N. Sen, X. Liu, Z. R. Craig, "Short term exposure to di-n-butyl phthalate (DBP) disrupts ovarian function in young CD-1 mice", Reproductive Toxicology, Vol. 53, pp. 15-22, 2015.

[13] A.L. Arancio, K.D. Cole, A.R. Dominguez, E.R. Cohenour, J. Kadie, W.C. Maloney, C. Cilliers, S.M. Schuh, "Bisphenol A, Bisphenol AF, di-n-butyl phthalate, and $17 \beta$-estradiol have shared and unique dose-dependent effects on early embryo cleavage divisions and development in Xenopus laevis", Reproductive Toxicology, Vol. 84, pp. 65-74, 2019.

[14] J. Hogberg, A. Hanberg, M. Berglund, S. Skerfving, M. Remberger, A.M. Calafat, A.F. Filipsson, B. Jansson, N. Johansson, M. Appelgren, H. Hakansson, "Phthalate diesters and their metabolites in human breast milk, blood or serum, and urine as biomarkers of exposure in vulnerable populations", Environmental Health Perspectives, Vol. 116, Issue 3, pp. 334339, 2008

[15] Y. Song, B. Salbu, L.S. Heier, H.C. Teien, O.C. Lind, D. Oughton, K. Petersen, B.O. Rosseland, L. Skipperud, K.E. Tollefsen, "Early stress responses in Atlantic salmon (Salmo salar) exposed to environmentally relevant concentrations of uranium", Aquatic Toxicology, Vol. 112, pp. 62-71, 2012.

[16] American Public Health Association (APHA), "Standard methods for the examination of water and waste water", 20th Edition, Washington, DC, 1998.

[17] M.U. Bergmeyer, "Steroid dehydrogenase. In: Methods of enzymatic analysis" Bergmeyer HU (Ed). Academic Press, New York, pp. 476-477, 1974.

[18] P. Hallgren, L. Martensson, L. Mathiasson, "Improved spectrophotometric vitellogenin determination via alkali-labile phosphate in fish plasma-a cost effective approach for assessment of endocrine disruption", International Journal of Environmental Analytical Chemistry, Vol. 89, Issue 14, pp. 1023-1042, 2009.

[19] O.H. Lowry, N.J. Rosebrough, A.L. Farr, R.J. Randall, "Protein measurement with the Folin phenol reagent", The Journal of Biological Chemistry, Vol. 193, pp.265-275, 1951.

[20] R.J. Roberts, D.A. Smail, "Laboratory methods", In: Ronald J. Roberts, Fish pathology. Edn 3, Harcourt publishers limited, pp.380-390, 2001.

[21] D.N. Weber, R.E. Spieler, "Behavioral mechanisms of metal toxicity in fishes", In: Malins DC, Ostrander GK. (Eds.), Aquatic toxicology: Molecular, biochemical and cellular perspectives. CRC Press, London, UK, pp 421-467, 1994.

[22] C. Wolter, R. Arlinghaus, "Navigation impacts on freshwater fish assemblages: the ecological relevance of swimming performance" Reviews in Fish Biology and Fisheries, Vol. 13, Issue 1, pp. 63-89, 2003.

[23] E.E. Little, S.K. Brewer, "Neurobehavioral toxicity in fish", In: Target organ toxicity in marine and freshwater teleosts new perspectives: Toxicology and the environment. Schlenk D, Benson WH (Eds.), Taylor and Francis, London and New York, Vol. 2, pp 139-174, 2001.

[24] S.R. Khalil, Y.A. Elhakim, A.E. El-Murr, "Sublethal concentrations of di-n-butyl phthalate promote biochemical changes and DNA damage in juvenile Nile tilapia (Oreochromis niloticus). Japanese Journal of Veterinary Research, Vol. 64, Issue 1, pp. 67-80, 2016.

[25] R.K. Poopal, M. Ramesh, V. Maruthappan, R.B. Rajendran, "Potential effects of low molecular weight phthalate esters $\left(\mathrm{C}_{16} \mathrm{H}_{22} \mathrm{O}_{4}\right.$ and $\left.\mathrm{C}_{12} \mathrm{H}_{14} \mathrm{O}_{4}\right)$ on the freshwater fish Cyprinus carpio, Toxicological Research, Vol. 6, Issue 4, pp. 505-520, 2017.

[26] H. Guo, S. Muhammad, Z. Zhang, T.R. Pavase, "Combined exposure of di (2-ethylhexyl) phthalate, dibutyl phthalate and acetyl tributyl citrate: Toxic effects on the growth and reproductive system of zebrafish (Danio rerio), International Journal of Environmental Science and Technology, Vol. 15, Issue 1, pp. 154-162, 2016

[27] K.L. Shepard, "Functions for fish mucus", Reviews in Fish Biology and Fisheries, Vol. 4, pp. 401-429, 1994.

[28] I. Salinas, "The mucosal immune system of teleost fish", Biology, Vol. 4. pp. 525-539, 2015.

[29] B.D. Wisenden, K. Barbour, "Antipredator responses to skin extract of redbelly dace, Phoxinus eos, by free-ranging populations of redbelly dace and fathead minnows, Pimephales promelas", Environmental Biology of Fish, Vol. 72, Issue 3, pp. 227-233, 2005.

[30] R.S. Sellers, D. Mortan, B. Michael, N. Roome, J.K. Johnson, B.L. Yano, R. Perry, K. Schafer, "Society of toxicologic pathology position paper: Organ weight recommendations for toxicology studies”, Toxicologic Pathology, Vol. 35, Issue 5, pp. 751-755, 2007.

[31] Y. Nagahama, M. Yoshikuni, M. Yamashita, T. Tokumoto, Y. Katsu, "Regulation of oocyte growth and maturation in fish", Current Topics in Developmental Biology, Vol. 30, pp. 103-145, 1995.

[32] M. Adir, C.M.H. Combelles, A. Mansur, L. Ophir, A. Hourvitz, R. Orvieto, J. Dor, R. Machtinger, "Dibutyl phthalate impairs steroidogenesis and a subset of LH-dependent genes in cultured human mural granulosa cell in vitro", Reproductive Toxicology, Vol. 69, pp. 13-18, 2017.

[33] V. Revathy, K.C. Chitra, "Di-isononyl phthalate (DINP) impairs reproduction in the freshwater fish, Oreochromis mossambicus (Peters 1852)", Asian Fisheries Science, Vol. 31, pp. 284-296, 2018.

[34] J.P. Sumpter, S. Jobling, "Vitellogenesis as a biomarker for estrogenic contamination of the aquatic environment", Environmental Health Perspectives, Vol. 103, Issue 7, pp. 173178, 1995.

[35] R.A. Wallace, K. Selman, "Cellular and dynamic aspects of oocyte growth in teleosts", American Zoologist, Vol. 21, Issue 2, pp. 325343, 1981 .

[36] H. Bhatia, A. Kumar, Y. Ogino, A. Gregg, J. Chapman, M.J. McLaughlin, T. Iguchi, "Di-n-butyl phthalate causes estrogenic effects in adult male Murray rainbow fish (Melanotaenia fluviatilis)", Aquatic Toxicology, Vol. 149, pp. 103-115, 2014.

[37] O. Carnevali, L. Tosti, C. Speciale, C. Peng, Y. Zhu, F. Maradonna, "DEHP impairs zebrafish reproduction by affecting critical factors in oogenesis", PLoS One Vol. 5, Issue 4, pp. e10201, 2010.

[38] Y. Nagahama, M. Yamashita, "Regulation of oocyte maturation in fish", Development Growth and Differentiation, Vol. 50, Issue 1, pp. S195-219, 2008.

[39] B. Querat, A. Sellouk, C. Salmon, "Phylogenetic analysis of the vertebrate glycoprotein hormone family including new sequences of sturgeon (Acipenser baeri) beta subunits of the two 
gonadotropins and the thyroid-stimulating hormone", Biology of Reproduction, Vol. 63, Issue 1, pp. 222-228, 2000.

[40] K. Ogiwara, C. Fujimori, S. Rajapakse, T. Takahashi, "Characterization of luteinizing hormone and luteinizing hormone receptor and their indispensable role in the ovulatory process of the medaka", PLoS One, Vol. 8, Issue 1, pp. e54482, 2013.

[41] H.F. Kwok, W.K. So, Y. Wang, W. Ge, "Zebrafish gonadotropins and their receptors: I. Cloning and characterization of zebrafish follicle-stimulating hormone and luteinizing hormone receptors-evidence for their distinct functions in follicle development", Biology of Reproduction,Vol. 72, Issue 6, pp. 1370-1381, 2005.

[42] Z. Yaron, G. Gur, P. Melamed, H. Rosenfeld, A. Elizur, B. Levavi-Sivan, "Regulation of fish gonadotropins", International Review of Cytology, Vol. 225, pp. 131-185, 2003.

[43] G. Paul, R.N. Binitha, F. Sunny, "Fish short-term reproductive assay for evaluating the estrogenic property of a commonly used antioxidant, butylated hydroxyanisole", Current Science, Vol. 115, Issue 8, pp. 1584-1587, 2018.

[44] H. Bhatia, A. Kumar, J. Du, J. Chapman, M.J. McLaughlin, "Di-nbutyl phthalate causes antiestrogenic effects in female Murray rainbowfish (Melanotaenia fluviatilis)", Environmental Toxicology and Chemistry, Vol. 32, Issue 10, pp. 2335-2344, 2013.

[45] J.F. Kerr, A.H. Wyllie, A.R. Currie, "Apoptosis: a basic biological phenomenon with wide-ranging implications in tissue kinetics", British Journal of Cancer 1972; 26(4): 239-257.

[46] J.L. Tilly, "Apoptosis and ovarian function", Reviews in Reproduction, Vol. 1, pp. 162-172, 1996.

[47] Z.R. Craig, P.R. Hannon, W. Wang, A. Ziv-Gal, J.A. Flaws, "Din-butyl phthalate disrupts the expression of genes involved in cell cycle and apoptotic pathways in mouse ovarian antral follicles", Biology of Reproduction, Vol. 88, Issue 1, pp. 1-10, 2013.

[48] P. E. Drevnick, M.B. Sandheinrich, J.T. Oris, "Increased ovarian follicular apoptosis in fathead minnows (Pimephales promelas) exposed to dietary methylmercury", Aquatic Toxicology, Vol. 79, Issue 1, pp. 49-54, 2006.

[49] T. Zhang, L. Li, X.S. Qin, Y. Zhou, X.F. Zhang, L.Q. Wang, M. De Felici, H. Chen, G.Q. Qin, W. Shen, "Di-(2-ethylhexyl) phthalate and bisphenol A exposure impairs mouse primordial follicle assembly in vitro", Environmental and Molecular Mutagenesis, Vol. 55, Issue 4, pp. 343-353, 2014.

\section{AUTHORS PROFILE}

K. Sajla presently pursuing M. Phil degree in the Department of Zoology, University of Calicut, Kerala, India in the area of Aquatic Toxicology. K. P. Raibeemol is doing Ph. D in the Department of Zoology and she is a recipient of Senior Research Fellow from UGC-Moulana Azad National Fellowship. K. C. Chitra is presently working as Associate Professor in the Department of Zoology, University of Calicut, India. 